\title{
Profound bradycardia after amyl nitrite in patients with a tendency to vasovagal episodes
}

\author{
MAXINE H ROSOFF, MICHAEL V COHEN \\ From the Division of Cardiology, Montefiore Medical Center and Albert Einstein College of Medicine, Bronx, \\ New York, USA
}

SUMMARY Two patients with mild aortic insufficiency inhaled amyl nitrite during routine echocardiographic examinations. One developed sinus arrest and syncope and the other had pronounced sinus bradycardia. The mechanism of this paradoxical response is unclear. Caution should be exercised when amyl nitrite is administered for diagnostic purposes.

Amyl nitrite is routinely used during physical and echocardiographic examinations for the evaluation of cardiac murmurs. This vasoactive agent generally causes dilatation of peripheral arteries and veins and striking tachycardia. We report an atypical and potentially dangerous response to amyl nitrite in two patients.

\section{Case reports}

\section{PATIENT 1}

A 32 year old man was referred for echocardiography for evaluation of a murmur after he had fainted when a phlebotomy needle was inserted. On another occasion, he had noted pronounced lightheadedness after blood donation. He denied other symptoms of cardiac disease. Physical examination revealed a short murmur of aortic regurgitation.

A baseline $M$ mode echocardiogram performed with the patient supine was normal. Resting heart rate was 58 beats per minute. Seconds after inhaling amyl nitrite, and while he was still supine, the patient complained of lightheadedness. The technician noted that the patient was sweating profusely, and shortly afterwards he became unresponsive. Figure (a) is the $M$ mode echocardiogram at the level of the mitral valve obtained immediately before and immediately after onset of the syncopal episode. After amyl nitrite inhalation the patient's heart rate initially slowed to 40 beats per minute. All atrial and ventricular electrical activity disappeared, and

Requests for reprints to Dr Maxine H Rosoff, Division of Cardiology, Montefiore Medical Center, 111 East 210th Street, Bronx, New York 10467, USA.

Accepted for publication 5 August 1985 recorded cardiac motion ceased for $10 \mathrm{~s}$. The technician attempted to arouse the patient, who became responsive after 3-5 s. Resumption of the echocardiographic record showed three junctional beats, followed by sinus rhythm at 60 beats per minute. When he was examined shortly after the episode the patient was peripherally constricted and sweating and complained of mild dizziness. The pulse rate was 56 beats per minute, blood pressure $110 / 70 \mathrm{~mm}$ $\mathrm{Hg}$, and the respiratory rate was 18 per minute. Cardiovascular and neurological examinations were unremarkable and repeat $\boldsymbol{M}$ mode and cross sectional echocardiograms were normal. The results of carotid sinus massage, hyperventilation, biochemical analysis of blood, 24 hour ambulatory electrocardiographic monitoring, and exercise stress test did not disclose any abnormality. The patient was told to avoid venepuncture. He remains symptom free.

\section{PATIENT 2}

A 32 year old man was referred for evaluation of a murmur that had been detected one month earlier at routine physical examination. He complained of severe anxiety leading to nausea, lightheadedness, sweating, and syncope. He recalled at least eight previous syncopal events, all associated with either medical visits or venepuncture. He had no other cardiac symptoms. Physical examination was normal apart from a I/IV early diastolic decrescendo blowing murmur at the base of the heart. Electrocardiogram and chest radiography were normal. $M$ mode echocardiographic examination showed fine diastolic fluttering of the anterior mitral leaflet with normal chamber dimensions. After inhalation of amyl nitrite the sinus rate fell progressively from 78 
to 30 beats per minute (Fig. (b)) and the patient complained of lightheadedness. The pulse rate then increased gradually.

Electrocardiographic examination during carotid sinus massage and hyperventilation, cross sectional echocardiography, 24 hour ambulatory electrocardiographic monitoring, and exercise stress test showed no abnormalities.

\section{Discussion}

These two apparently healthy patients had paradoxical bradycardia after inhalation of amyl nitrite. One had sinus arrest with loss of consciousness while supine. Although both had short murmurs characteristic of aortic insufficiency, neither had evidence of haemodynamically important cardiovascular disease. They were taking no medications. To our knowledge, sinus bradycardia and arrest after amyl nitrite inhalation have not been described before.
Inhaled amyl nitrite enters the circulation rapidly, producing sudden and pronounced arteriolar and venous dilatation. The fall in systemic blood pressure results in reflex stimulation of the sympathetic nervous system, producing sinus tachycardia and pronounced venoconstriction, both of which contribute to the increase in cardiac output. Reflex arteriolar constriction occurs as well. ${ }^{12}$ Amyl nitrite induces more pronounced reflex vasoconstriction than glyceryl trinitrate.

In patients with severe coronary stenosis, cardiac output may fall after nitrate administration if the induced hypotension intensifies ischaemia. ${ }^{3}$ Come and Pitt described syncope in five patients with myocardial infarction. ${ }^{4}$ They developed hypotension and bradycardia without preceding tachcardia after they had been given sublingual or intravenous glyceryl trinitrate in the first $\mathbf{2 4}$ hours after myocardial infarction.

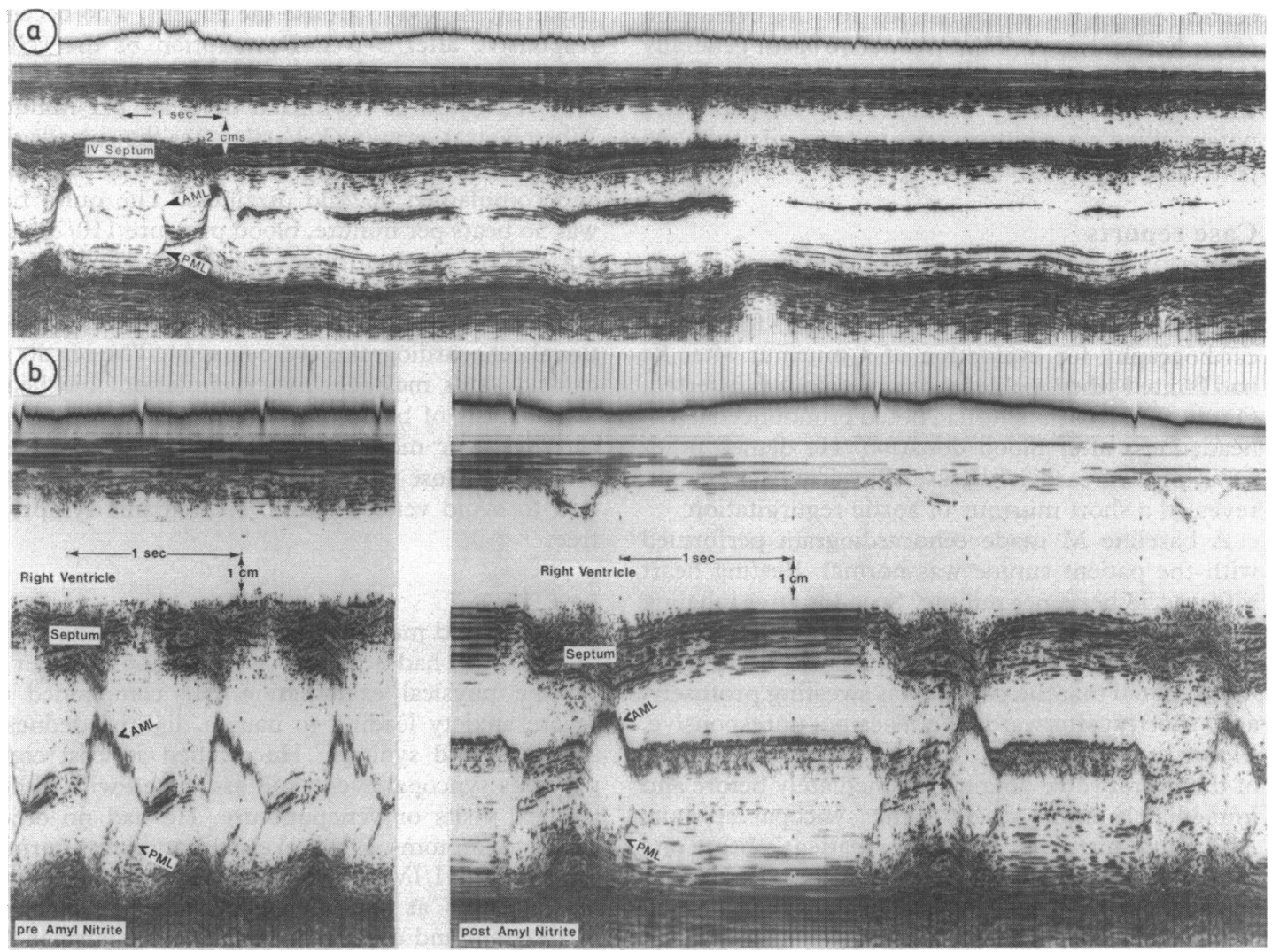

Figure $M$ mode echocardiograms at the level of the mitral valve several seconds after amyl nitrite inhalation. (a) In patient 1 two sinus beats were followed by prolonged asystole. (b) In patient 2 the sinus rate slowed to 30 beats per minute. There is evidence of diastolic fluttering of the mitral valve. AML, anterior mitral leaflet; PML, posterior mitral leaflet; IV septum, interventricular septum. 
Nitrate induced syncope is not restricted to patients with coronary artery disease. ${ }^{56}$ Studies of normal volunteers on tilt tables have suggested that decreased effective circulating blood volume secondary to dependent venous pooling may cause circulatory collapse, ${ }^{78}$ and that this reaction may be intensified by the administration of sodium nitrite. ${ }^{910}$ Such reactions are characterised by constant central venous pressure, gradually falling arterial pressure, and complaints of sweating, nausea, abdominal cramps, and dizziness. Abrupt falls in blood pressure and heart rate may follow. Loss of consciousness may be prevented by returning the subjects to the supine position, negative pressure breathing, or albumin infusion. Atropine prevents bradycardia but not syncope. These haemodynamic responses have been ascribed to parasympathetic reflexes induced by ischaemia of the medulla oblongata $^{10}$ or by left ventricular cavitary obliteration. ${ }^{8}$ The theory that cerebral ischaemia causes the bradycardia has been questioned because changes in heart rate precede electroencephalographic changes. In the two patients described here, there was no obliteration on the $M$ mode echocardiograms at the time the haemodynamic changes occurred.

Vagal reflexes are often implicated in syncope associated with bradycardia. Because reflex asystole rarely lasts more than $10 \mathrm{~s}$, and $15 \mathrm{~s}$ of asystole are generally required to produce unconsciousness in the recumbent position, reflex mediated syncope is unusual in a supine patient. ${ }^{11}$ There are multiple afferent pathways which may lead to vagally induced bradycardia, asystole, and vasodilatation. Afferent fibres originate in the heart, arterial vessels, respiratory and gastrointestinal tracts, the ear, and the trigeminal and glossopharyngeal nerves. Hypersensitivity is extremely variable, and is subject to influences such as hypoxia and medications. ${ }^{12}$ There are many intracardiac reflexes. ${ }^{13}$ The coronary chemoreflex, also mediated by the vagus nerve, produces a fall in blood pressure and heart rate after intracoronary injection of chemicals such as digitalis, nicotine, adenosine triphosphate, serotonin, phenyl diguanide, and isothiourea. ${ }^{1415}$ The effects of amyl nitrite on this reflex have not been examined. Cardiac pressor reflexes after an increase of intracavitary pressures result in bradycardia and hypotension. ${ }^{1617}$ Intense vasodilatation and bradycardia, as well as decreased venous return, have been induced in dogs by acute increases in left ventricular pressure. ${ }^{18-20}$ Appreciable increases in left ventricular pressure after amyl nitrite administration, however, have not been demonstrated.

Glossopharyngeal neuralgia may cause bradycardia and syncope, ${ }^{21}$ and similar bradycardias have been described in patients with "swallow syncope" in association with oesophageal lesions. ${ }^{2223}$ Our patients had no history of mandibular pain or symptoms referable to the oesophagus. Several inhaled gases, such as ammonia, phosgene, and bromine vapour, cause vagally mediated reductions in heart rate and blood pressure. These may act on chemoreceptors in the lung or may be systemically absorbed and act at other sites. ${ }^{12}$. Amyl nitrite, despite its broad clinical use, has not been associated with pulmonary chemoreflexes.

Because these patients were told to inhale deeply when amyl nitrite was administered, some degree of hyperventilation induced hypocapnia may have resulted. Hypocapnia intensifies cerebral vasoconstriction, ${ }^{24}$ and, therefore, may contribute to centrally mediated syncope. Neither patient, however, developed symptoms of hypocapnia, nor did hyperventilation at a later time reproduce the bradycardia or syncope.

The cause of the bradycardia in these patients is unclear. Neither of the patients responded to amyl nitrite with early tachycardia. In patient 1 , a trained athlete, relative insensitivity of cardiac beta receptors may have contributed to lack of a chronotropic response, ${ }^{25}$ but patient 2 had a sedentary lifestyle. In both, bradycardia was the first manifestation of this unusual reaction.

It is important to note that bradycardia and sinus arrest may occur as an unexpected reaction to amyl nitrite inhalation. Administration of this agent has been considered to be a routine procedure without known serious sequelae. Although the complication noted in this report is probably rare, we feel that the use of amyl nitrite should be avoided in patients with unexplained syncope. This agent should be administered by staff who are trained in cardiopulmonary resuscitation and atropine and appropriate resuscitative equipment should be available.

We thank Dr Dennison Young for permission to describe his patient.

\section{References}

1 Mason DT, Braunwald E. The effects of nitroglycerin and amyl nitrite on arteriolar and venous tone in the human forearm. Circulation 1971; 32: 755-66.

2 Mason DT, Zelis R, Amsterdam EA. Actions of the nitrites on the peripheral circulation and myocardial oxygen consumption: significance in the relief of angina pectoris. Chest 1971; 59: 296-305.

3 Delgado CE, Pitt B, Taylor DR, Weisfeldt ML, Kelly DT. Role of sublingual nitroglycerin in patients with acute myocardial infarction. $\mathrm{Br}$ Heart $\mathcal{F}$ 1975; 37: $392-6$. 
4 Come PC, Pitt B. Nitroglycerin-induced severe hypotension and bradycardia in patients with acute myocardial infarction. Circulation 1976; 54: 624-8.

5 Prodger SH, Ayman D. Harmful effects of nitroglycerin with special reference to coronary thrombus. Am f Med Sci 1932; 184: 480-91.

6 Sprague HB, White PD. Nitroglycerin collapse: a potential danger in therapy. Med Clin North Am 1933; 16: 895-9.

7 Weissler AM, Warren JV, Estes EH Jr, McIntosh HD, Leonard JJ. Vasodepressor syncope: factors influencing cardiac output. Circulation 1957; 15: 875-82.

8 Epstein SE, Stampfer M, Beiser GD. Role of the capacitance and resistance vessels in vasovagal syncope. Circulation 1968; 37: 524-33.

9 Weiss S, Ellis LB. Influence of sodium nitrite on the cardiovascular system and on renal activity in health, in arterial hypertension, and in renal disease. Arch Intern Med 1933; 52: 105-19.

10 Weiss S, Wilkins RW, Haynes FW. The nature of circulatory collapse induced by sodium nitrite. $f$ Clin Invest 1937; 16: 73-84.

11 McIntosh HD, Estes EH, Warren JV. The mechanism of cough syncope. Am Heart $\mathcal{F}$ 1956; 52: 70-82.

12 Engel GL. Fainting. 2nd ed. Springfield, Illinois: Charles C Thomas, 1962: 50-102.

13 Wayne HH. Syncope. Am F Med 1961; 30: 418-38.

14 Dawes GS, Comroe JH Jr. Chemoreflexes from the heart and lungs. Physiol Rev 1954; 34: 167-201.

15 Comroe JH Jr, Van Lingen B, Stroud RC, Roncoroni A. Reflex and direct cardiopulmonary effects of 5-OH-tryptamine (Serotonin). Am F Physiol 1953; 173: 379-86.
16 Aviado DM Jr, Li TH, Kalow W, et al. Respiratory and circulatory reflexes from the perfused heart and pulmonary circulation of the dog. Am f Physiol 1951; 165: 261-77.

17 Aviado DM Jr, Schmidt CF. Reflexes from stretch receptors in blood vessels, heart and lungs. Physiol Rev 1955; 35: 247-300.

18 Aviado DM Jr, Schmidt CF. Cardiovascular and respiratory reflexes from the left side of the heart. $A m \mathcal{F}$ Physiol 1959; 196: 726-30.

19 Ross J Jr, Frahm CJ, Braunwald E. The influence of intracardiac baroreceptors on venous return, systemic vascular volume and peripheral resistance. $\mathcal{F}$ Clin Invest 1961; 40: 563-72.

20 Walker JL, Thames MD, Abboud FM, Mark AL, Klopfenstein HS. Preferential distribution of inhibitory cardiac receptors in left ventricle of the dog. Am f Physiol 1978; 235: H188-92.

21 Kong Y, Heyman A, Entman ML, McIntosh HD. Glossopharyngeal neuralgia associated with bradycardia, syncope and seizures, Circulation 1964; 30: 109-13.

22 Waddington JKB, Matthews HR, Evans CC, Ward DW. Carcinoma of the oesophagus with "swallow syncope" [Letter]. Br Med f 1975; iii: 232.

23 Wik B, Hillestad L. Deglutition syncope. $\mathrm{Br}$ Med $\mathcal{f}$ 1975; iii: 747.

24 Karp HR, Weissler AM, Heyman A. Vasodepressor syncope: EEG and circulatory changes. Arch Neurol 1961; 5: 94-101.

25 Brundin T, Cernigliaro C. The effect of physical training on the sympathoadrenal response to exercise. Scand f Clin Lab Invest 1975; 35: 525-30. 